\title{
Interactive comment on "Long-term profiling of aerosol light-extinction, particle mass, cloud condensation nuclei, and ice-nucleating particle concentration over Dushanbe, Tajikistan, in Central Asia" by Julian Hofer et al.
}

Anonymous Referee \#1

Received and published: 10 January 2020

This paper presents comprehensive analysis of the lidar observation in Dushanbe, Tajikistan in the Central Asian Dust Experiment (CADEX). The manuscript is well written in general. The analysis relies on the POLIPHONE method. Although references are suitably cited and accuracy estimates are given, it would be helpful if brief descriptions on the basic concept of the POLIPHONE method and assumptions involved in the method.

Specific comments: Table 1: It seems "bd" and "bc" in Table 1 are not explained. Figure 5: What is the reason for changing the trajectory arriving height with season? The

Printer-friendly version

Discussion paper 
difference in trajectory may be due to the difference in the arriving height. Would it be possible to give more comprehensive presentation of the trajectory cluster analysis? Figure 13 and 14: What is the definition of the top height of dust layer? Figure 17 and 18: It is difficult to understand exactly the difference between these figures. If I understand correctly, the parameterization to estimate INP is dependent on temperature, but constant temperature (-25degC and $-50 \mathrm{deg} C$ for immersion and deposition nucleation) was used in Figure 17. In Figure 18, INP was derived for each lidar profile using actual temperature profile, and INP profiles were averaged later. Is that correct?

Interactive comment on Atmos. Chem. Phys. Discuss., https://doi.org/10.5194/acp-2019-963, 2019. 